\title{
Lesiones de los tendones extensores
}

\section{Del Cerro Gutiérrez ${ }^{(\mathrm{I})}$, F. Corella Montoya ${ }^{(\mathrm{I}, 2)}$, M. OCAMPOS HERNÁNDEZ ${ }^{(1,2)}$}

(1) Unidad de Cirugía de la Mano. Hospital Beata María Ana. Madrid

(2) Unidad CE Cirugía de la Mano. Hospital INFANTA LEONor MAdRID

Correspondencia:

migueldelcerro@yahoo.es

\section{INTRODUCCIÓN}

T

a lesión de los tendones extensores, considerada muchas veces como "lesión de menor importancia", es mucho más frecuente que la de los flexores, no tan fácil de tratar $\mathrm{y}$, desgraciadamente suele tratarse en los quirofanitos de urgencia por el personal menos entrenado.

La anatomía de estas estructuras, sobre todo a nivel distal es bastante más compleja que la de los tendones flexores, tienen menor deslizamiento que estos (de ahí la importancia de mantener su longitud) y los resultados no son tan sencillos de obtener como erróneamente se piensa. Distintos estudios demuestran la gran importancia del tratamiento inicial en el resultado final ${ }^{1}$.

\section{LESIONES DEDOS TRIFALÁNGICOS}

\section{Clasificación}

La clasificación más aceptada de las zonas del dorso de la mano que nos va a permitir definir la lesión de los extensores es la realizada por Kleinert y Verdan en el año 1983 y posteriormente aceptada por la FISSH. Esta clasificación define ocho zonas en función de la localización de la lesión ${ }^{2}$.

Zonas impares: son las articulaciones. I: interfalángica distal (IFD), III: interfalángica proximal (IFP), V: metacarpofalángica (MCF) y VII: carpo (retináculo extensor)

Zonas pares: entre las anteriores II: falange media, IV: falange proximal VI: metacarpianos VIII: antebrazo distal (Figura 1)
Las lesiones pueden ser agudas o ser diagnosticadas de forma tardía (crónicas). Las lesiones agudas pueden producirse por un corte, es decir ser abiertas o se pueden producir por un traumatismo sin herida, es decir ser cerradas.

El esquema del presente trabajo consistirá en describir zona a zona las distintas lesiones que pueden presentar los pacientes y el tratamiento de cada una de ellas.

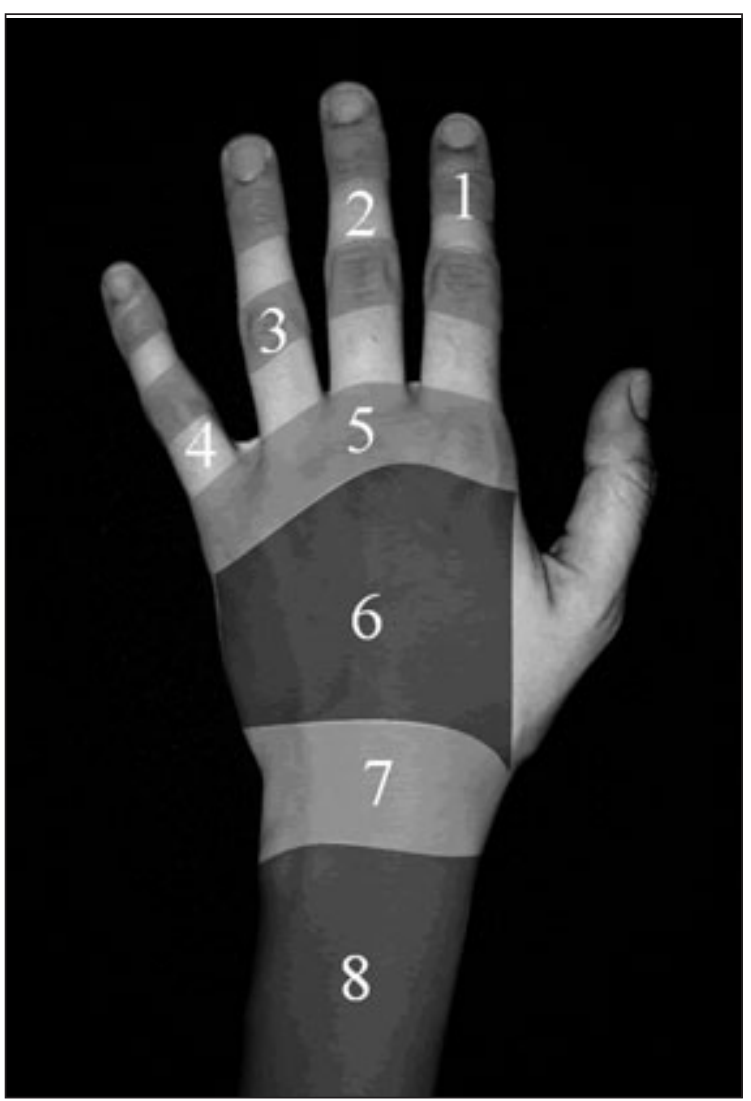

Figura 1: Zonas de Kleinert y Verdan². 


\section{Zona I}

La lesión del extensor a nivel de IFD produce lo que se conoce como dedo en martillo (Figura 2).

Si se trata de una lesión abierta, la primera dificultad que encontraremos es el poco tendón que queda para realizar la sutura.

Por eso muchos autores lo que recomiendan es realizar una tenodermodesis: una sutura continua que englobe piel y tendón (Figura 3)

El postoperatorio precisa una inmovilización continua (día y noche) en extensión durante seis semanas y dos semanas más, como mínimo de férula nocturna.

Mucho más frecuente es que la lesión sea cerrada produciendo también una deformidad en "dedo en martillo" que habitualmente la tratamos de manera conservadora inmovilizando en extensión la IFD y permitiendo la movilidad de la IFP. El paciente debe llevar una férula durante 6 semanas de una manera continua y posteriormente por la noche entre 2 y 6 semanas más 3 .

Existen distintas férulas para realizar esta inmovilización. La más utilizada la férula de Stack (Figura 4) pero también puede utilizarse una férula de termoplástico o de aluminio.

Con este tratamiento se consigue un $80 \%$ de buenos resultados, considerando buen resultado un déficit de extensión de $10^{\circ}$.

En la lesión crónica, la mayoría de los autores recomiendan un tratamiento conservador mediante férula igual que en agudo incluso con meses de evolución.

Si fracasa el tratamiento conservador la solución es quirúrgica, pero, para saber qué tipo de intervención hay que realizar, debemos valorar el estado de la IFP: Si existe, o no, un dedo en cuello de cisne. ¿Por qué se produce el cuello de cisne tras un dedo en martillo? Porque la tracción repetida sobre la base de F2, hace que la bandeleta central hiperextienda la IFP y se distienda la placa volar y como no existe oposición a la tracción del flexor profundo, este tracciona de la inserción en F3 flexionando la IFD y apareciendo la deformidad de cuello de cisne (Figura 5).

Si no existe cuello de cisne, la técnica quirúrgica más utilizada para un dedo en martillo crónico es la descrita por Brooks y Granner: Resección de varios milímetros de piel y del ten-

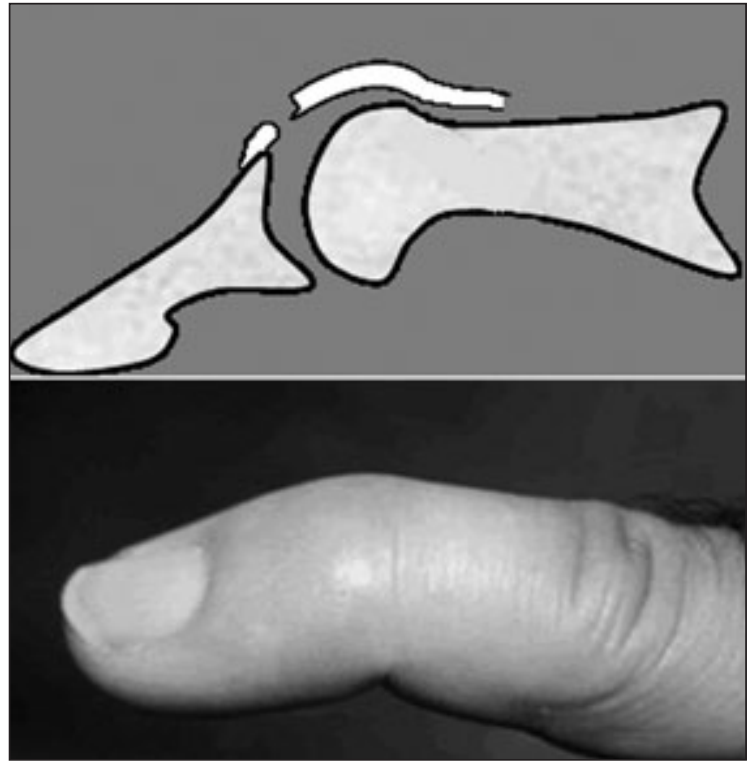

Figura 2: Dedo en martillo.

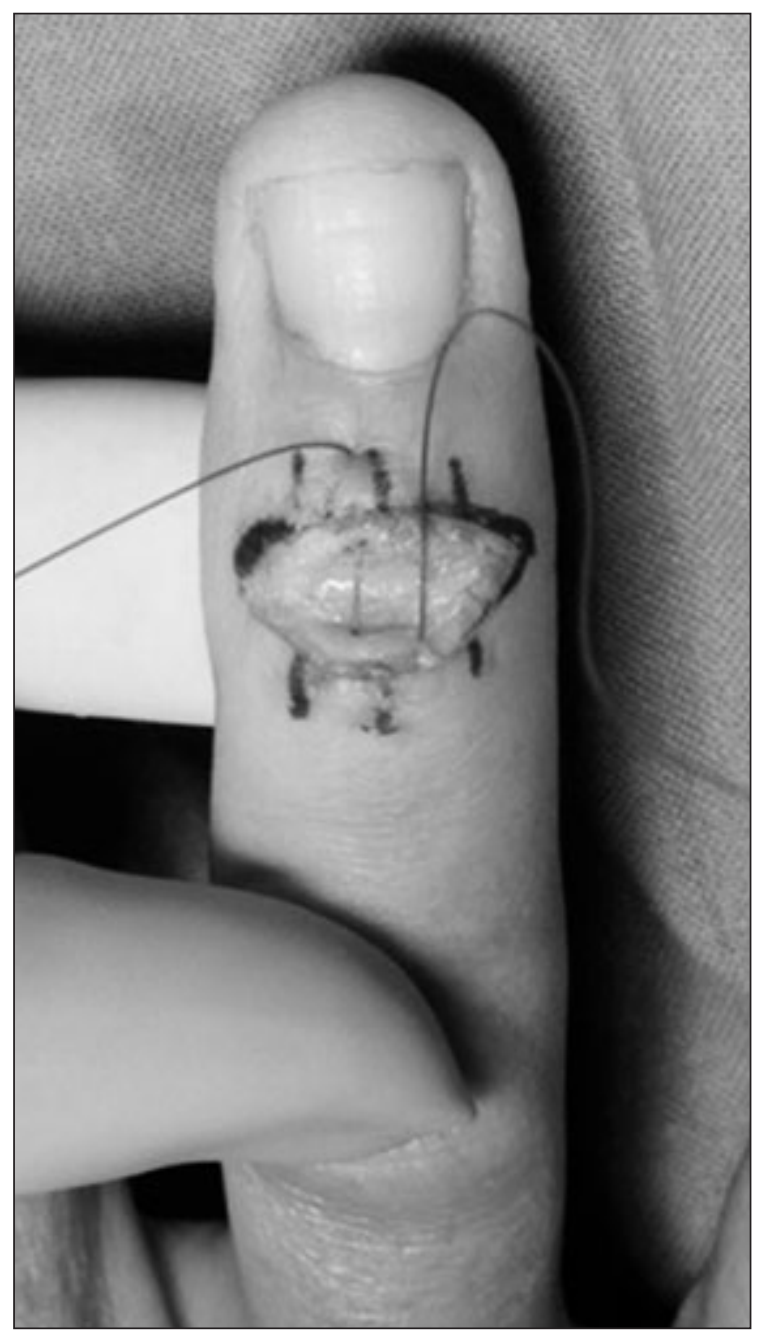

Figura 3: Tenodermodesis. 


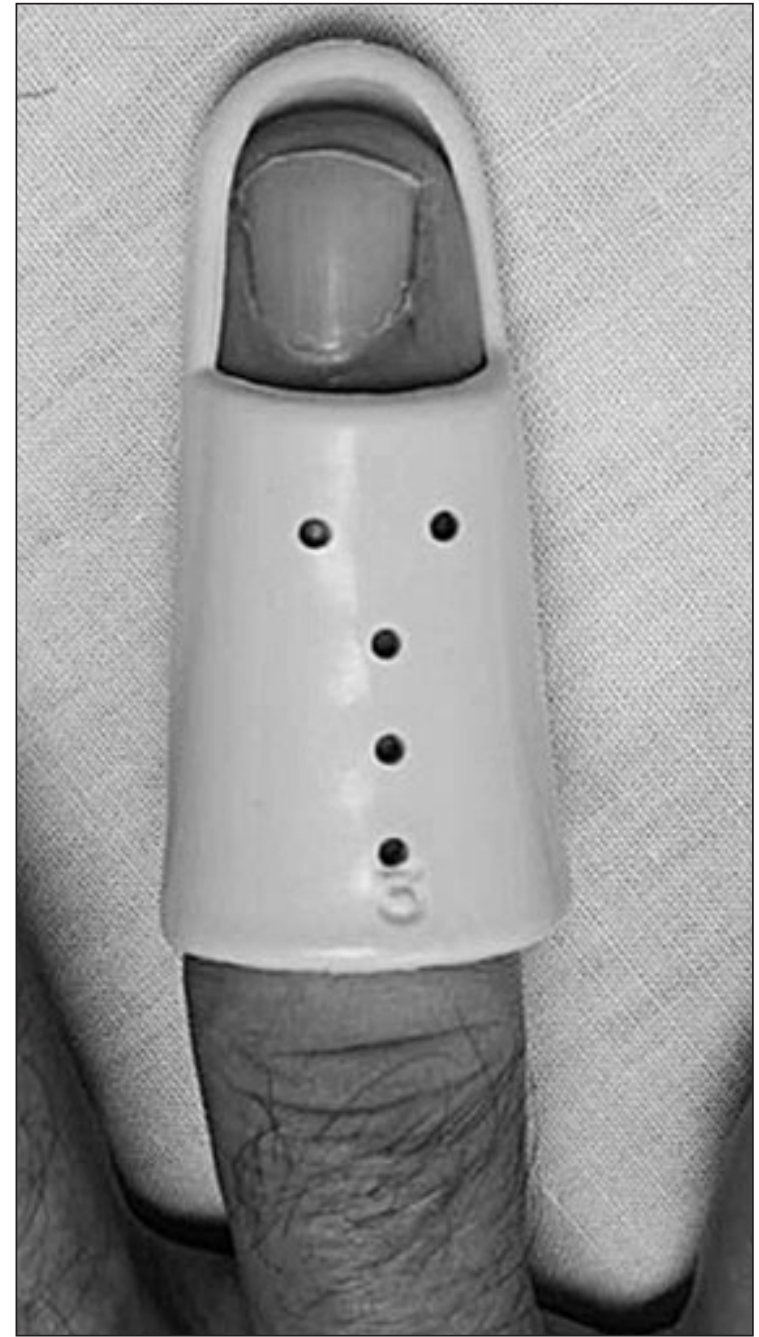

Figura 4: Férula de Stack.

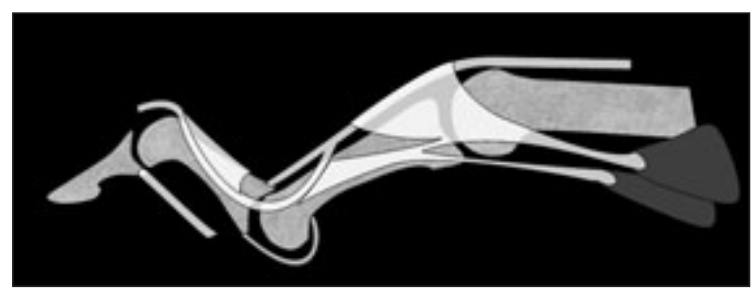

Figura 5: Cuello de cisne por dedo en martillo.

dón. Posteriormente se realiza una tenodermodesis (parecida a la lesión aguda) y por último se fija la IFD con una aguja unas 4-5 semanas ${ }^{4}$ (Figura 6).

Si existe cuello de cisne la técnica más aceptada es la descrita por Thompson que reconstruye el ligamento retinacular oblicuo con un injerto tendinoso de palmaris longus que fijamos mediante pull-out o arpones, a la parte lateral

de la base de F1 y al dorso de F3 pudiendo así flexionar IFP y extender IFD ${ }^{5}$ (Figura 7).

Doyle $^{6,7}$ clasificó estas lesiones en 4 tipos (Tabla I) que tiene un interés didáctico.

\section{Zona II}

Diáfisis de F2.

Las lesiones cerradas son indistinguibles de la zona 1 y se tratan igual que ellas.

Las lesiones crónicas que requieren tratamiento también son excepcionales en esta zona, su reconstrucción sería igual que la zona I.

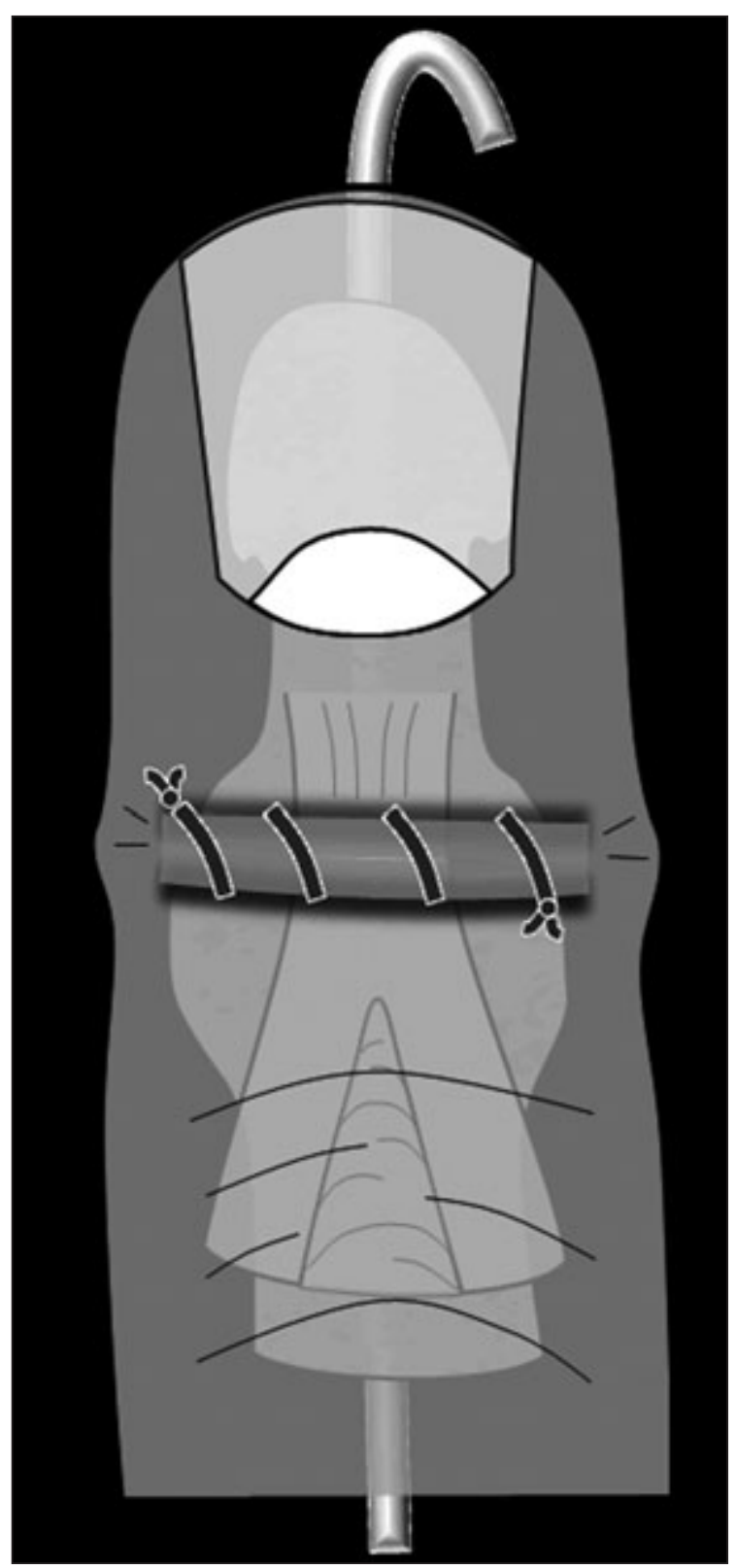

Figura 6: Técnica de Brooks y Graner.4.

Revista Iberoamericana de Cirugía de la Mano 

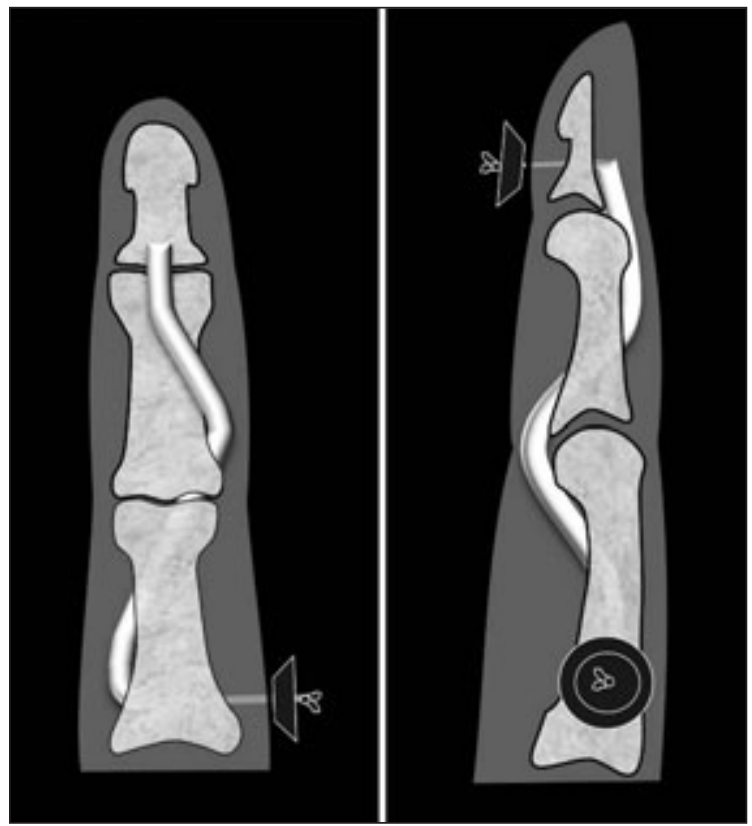

Figura 7: Técnica de SORL (Spiral Oblique Retinacular Ligament $)^{5}$.

\begin{tabular}{|c|l|}
\hline TIPO I & $\begin{array}{l}\text { Traumatismo cerrado con pérdida de conti- } \\
\text { nuidad tendinosa. Con o sin fractura-avul- } \\
\text { sión de pequeño tamaño. }\end{array}$ \\
\hline TIPO II & $\begin{array}{l}\text { Traumatismo abierto en IFP con pérdida de } \\
\text { continuidad tendinosa. }\end{array}$ \\
\hline TIPO III & $\begin{array}{l}\text { Abrasión profunda con pérdida de piel, teji- } \\
\text { do celular subcutáneo y tendón. }\end{array}$ \\
\hline TIPO IV & $\begin{array}{l}\text { A. Epifisiolisis en niños. } \\
\text { B. Lesión por hiperflexión con fractura de } \\
\text { la superficie articular entre el 20-50\%. } \\
\text { C. Lesión por hiperextensión con fractura } \\
\text { articular superior al 50\% y subluxación } \\
\text { volar de F3. }\end{array}$ \\
\hline
\end{tabular}

Tabla I: Dedo en martillo. Clasificación de Doyle ${ }^{6,7}$.

Hablaremos solamente de las lesiones agudas abiertas es decir, las que se producen por herida sobre la segunda falange.

En las secciones del tendón extensor en zona II lo que nos orienta al tratamiento es el tamaño de la lesión. Si es mayor o menor del $50 \%$ del tamaño del tendón.

Si la lesión es menor del 50\% no precisa reparación ya que una sola de las dos bandas laterales aseguran la función del tendón. En este caso se realiza cura de la herida e inmovilización de la IFD 7-10 días.

Por el contrario si la lesión es mayor del $50 \%$ si que precisa reparación
Doyle $^{6,7}$ recomienda que la sutura sea continua porque al ser muy plano el tendón, no podremos realizar una sutura central. Esta sutura continua, debe reforzarse con una sutura cruzada tipo Silfverskiöld (Figura 8).

Durante el postoperatorio mantendremos una inmovilización continua de la IFD 6 semanas, seguida de al menos dos semanas de inmovilización nocturna.

\section{Zona III}

Rotura de la bandeleta central del aparato extensor en su inserción sobre F2. Sin duda la más compleja de tratar. La lesión sobre la IFP produ-

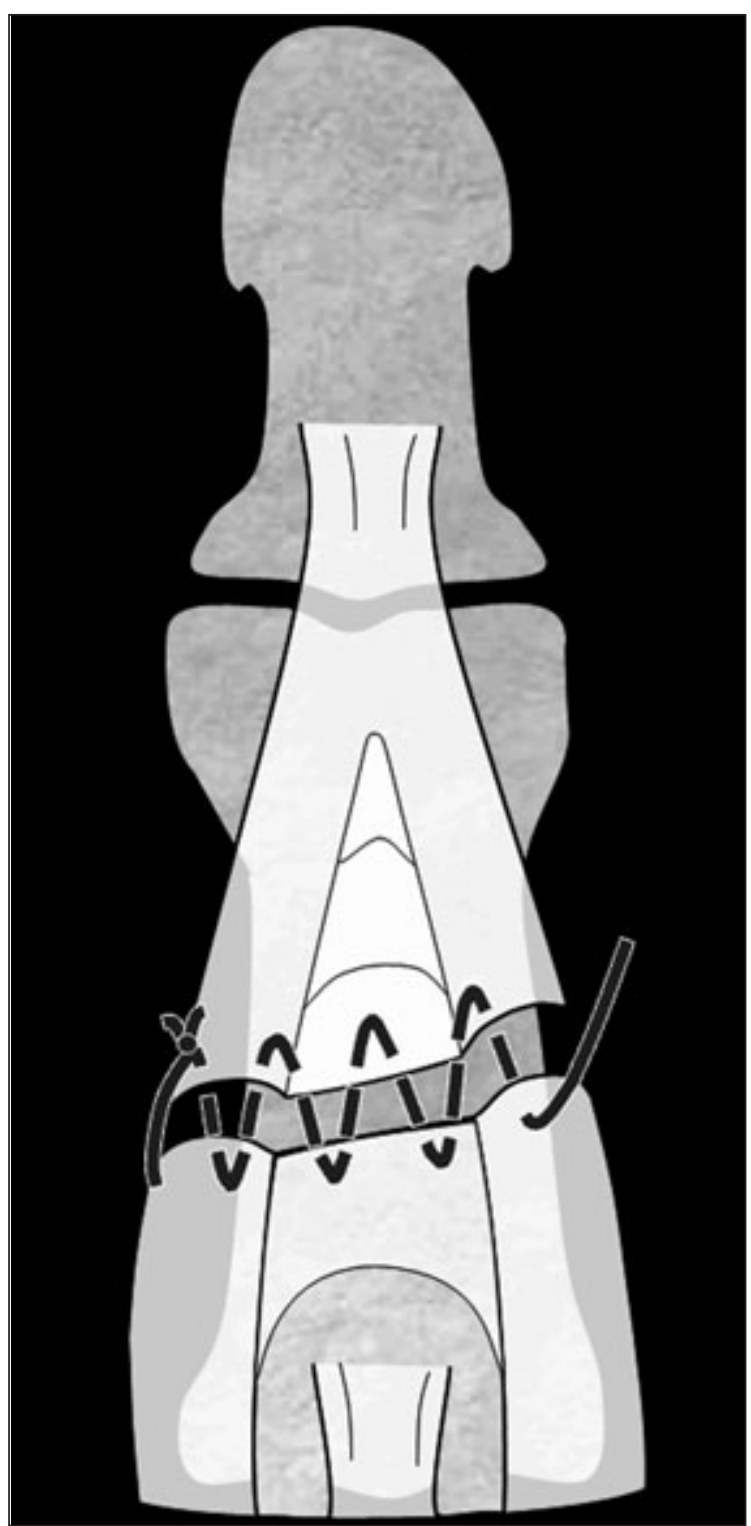

Figura 8: Sutura en zona II 
ce la deformidad en ojal (boutonnière) con actitud en flexo de la IFP y extensión de la IFD Esto es debido a que, al romperse la bandeleta central, la cabeza de F1 se luxa hacia dorsal con lo que el flexor digitorum superficialis flexiona F2 y las bandeletas laterales traccionarán de la IFD produciendo su hiperextensión (Figura 9).

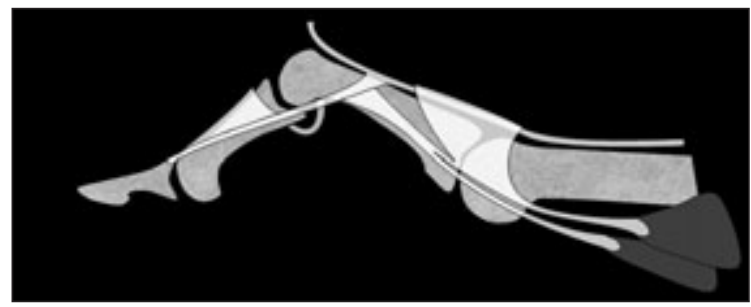

Figura 9: Zona III. Rotura bandeleta central.

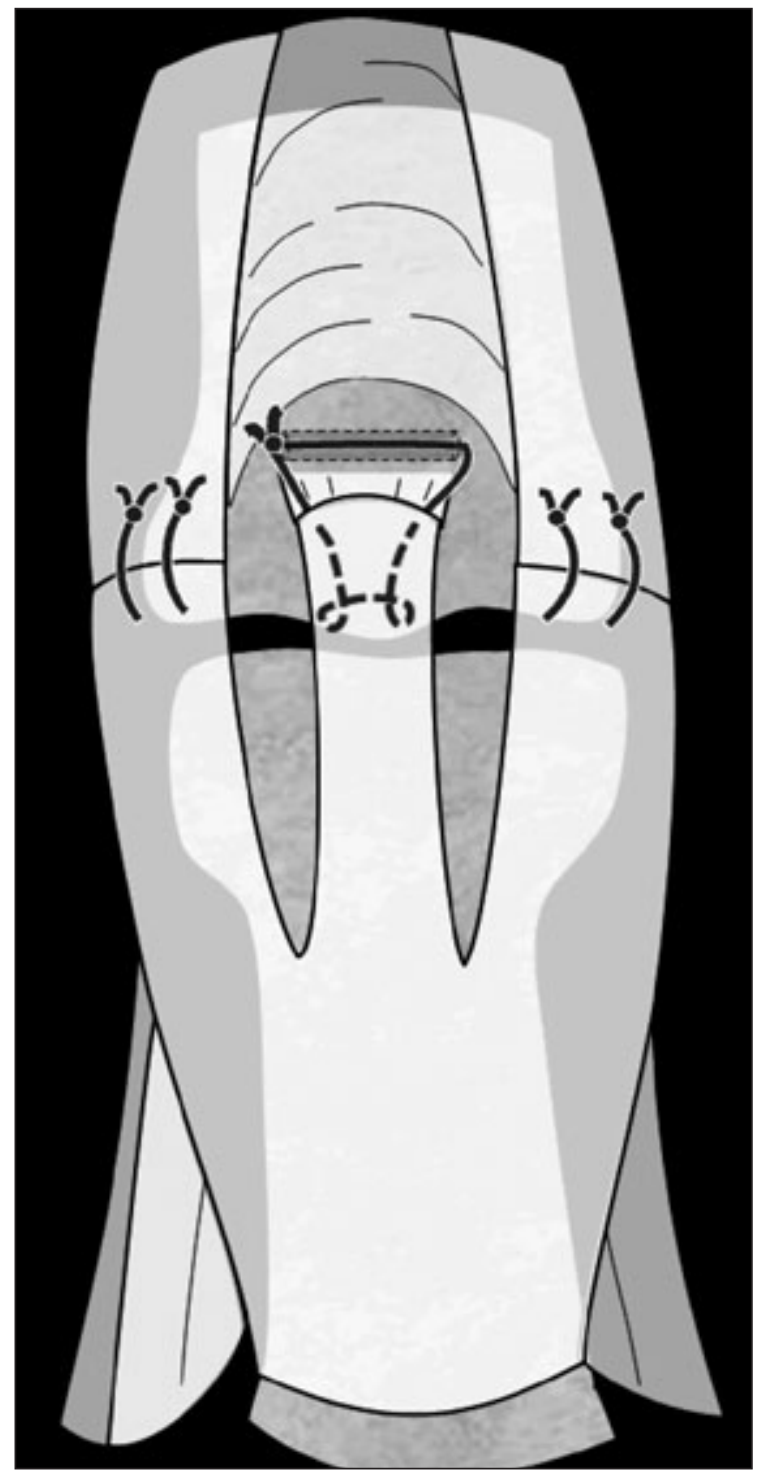

Figura 10: Sutura directa en Zona III.
Existen multitud de técnicas de tratamiento conservador y quirúrgico según el tipo de lesión y como en cualquier situación, si existen tantas es porque ninguna es perfecta. Repasaremos, por tanto, las más aceptadas. Veremos como siempre las lesiones agudas abiertas y cerradas y las lesiones crónicas. Ya hemos dicho que vamos a ocuparnos sólo de lesiones traumáticas ya que en esta zona ocurren también lesiones típicas de procesos reumatológicos.

\section{LESIÓN AGUDA ABIERTA EN ZONA III:} Seguimos el esquema de la tabla II, diferenciando si existe o no pérdida de sustancia. Si no hay pérdida de sustancia tendinosa, deberemos suturar las bandeletas laterales si estuviesen seccionadas y reinsertar la media (Figura 10). En el postoperatorio el paciente debe llevar una férula de inmovilización IFP en extensión dejando libre MCF e IFD, que deberá mover de una manera pasiva a diario durante 6 semanas. Al terminar este periodo debe llevar 6 semanas más la férula por la noche ${ }^{8}$.

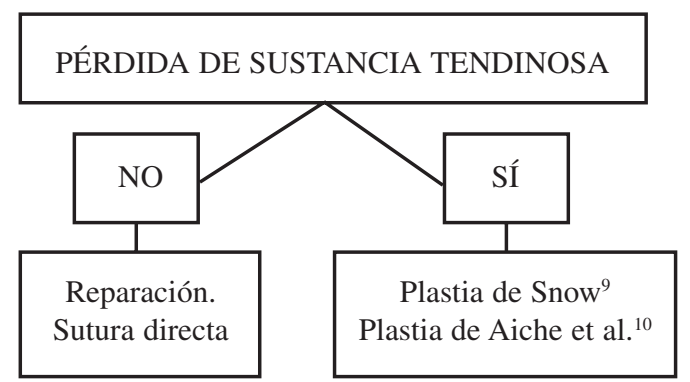

Tabla II: Lesión en ojal. Tratamiento.

Si hay pérdida de sustancia tendinosa realizaremos una plastia de Snow $^{9}$, con una tira de la bandeleta central girada $180^{\circ}$ sobre ella misma para cubrir el defecto de la bandeleta central (Figura 11), o una plastia de Aiche et al. ${ }^{10}$, sustituyendo la bandeleta media por dos colgajos tendinosos tomados de las bandeletas laterales (Figura 12).

\section{LESIÓN AGUDA CERRADA EN ZONA}

III: El traumatismo no produce la deformidad en ojal de una manera aguda. Suele tardar unos 10 días en aparecer la deformidad con lo que el diagnóstico inicial es difícil de realizar. Tendremos una sospecha clínica por la falta de ex- 


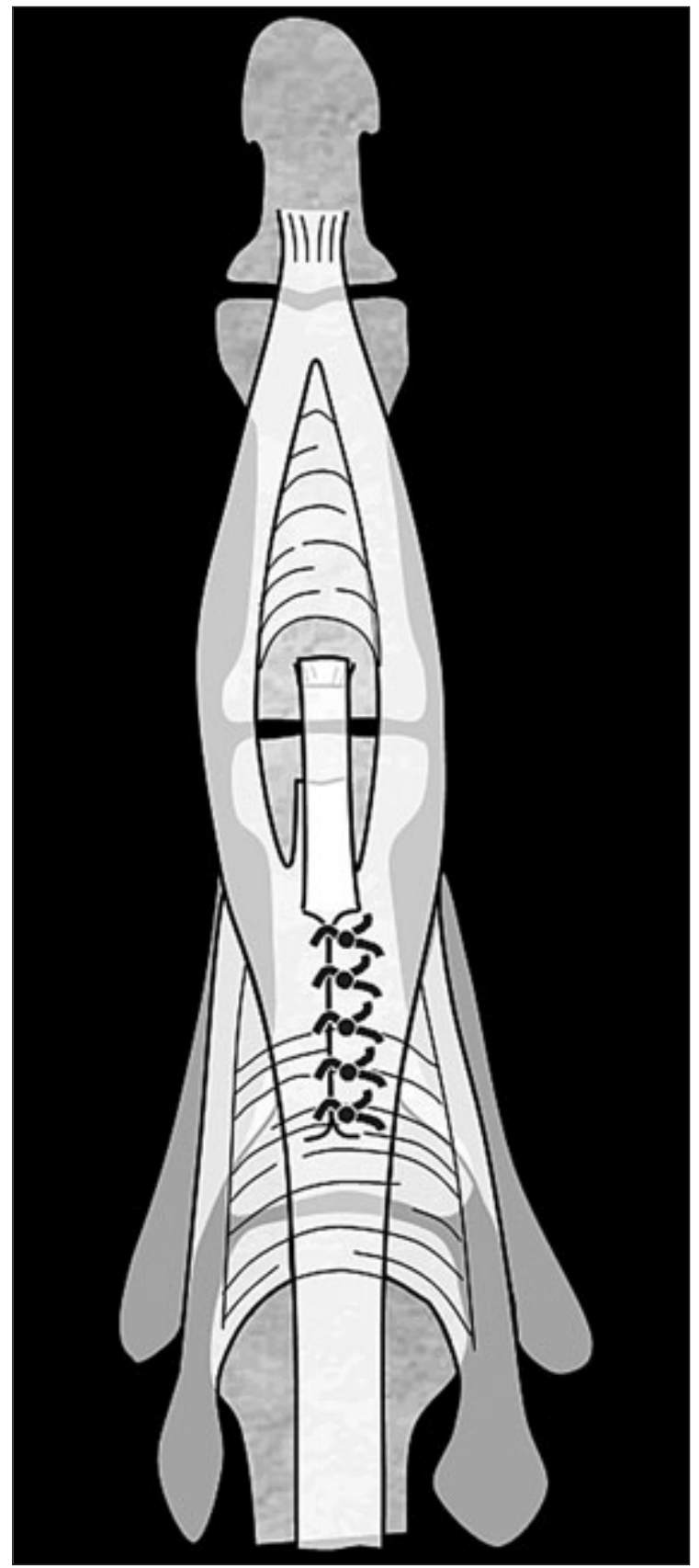

Figura 11: Plastia de Snow ${ }^{9}$.

tensión o la pérdida de fuerza de la IFP. Existe un test descrito por Carducci ${ }^{11}$ que consiste en flexionar la muñeca y la MCF, se pide al paciente que realice una extensión de la IFP y tiene un déficit de $15-20^{\circ}$, hay que sospechar una lesión en ojal (Figura 13).

En cuanto a su tratamiento, la mayoría de los autores abogan por un tratamiento conservador, inmovilizando con una férula la IFP y dejando libre IFD y la MCF, durante un periodo de 6 sema-

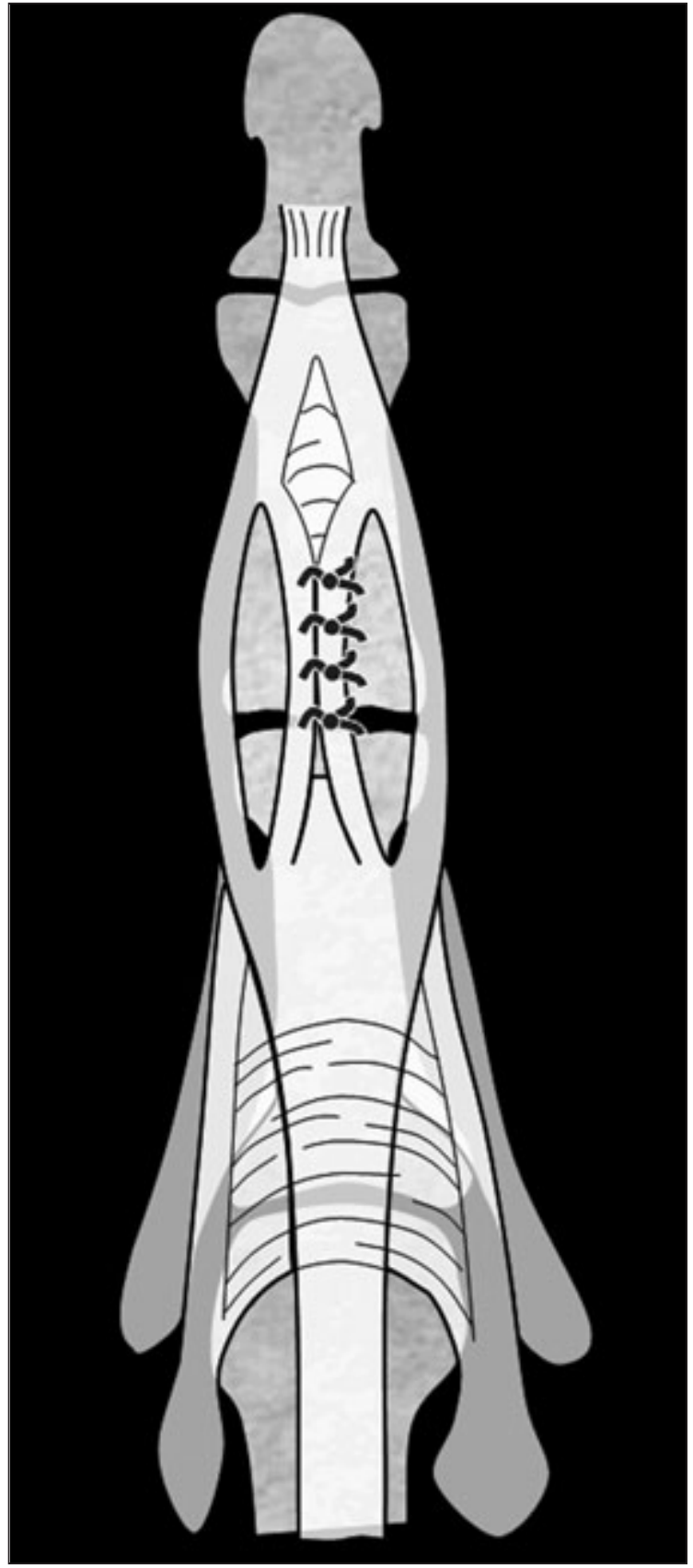

Figura 12: Plastia de Aiche et al. ${ }^{10}$.

nas de una manera continua y otras 6 solo por la noche ${ }^{12}$, aunque otros defienden la movilización precoz en un arco corto de movilidad frente a la inmovilización clásica ${ }^{13}$.

Se considera un resultado satisfactorio una flexión completa aunque haya un déficit de $20^{\circ}$ de extensión.

LESIÓN CRÓNICA EN ZONA III: Para valorar el tratamiento de la lesión crónica en ojal, 


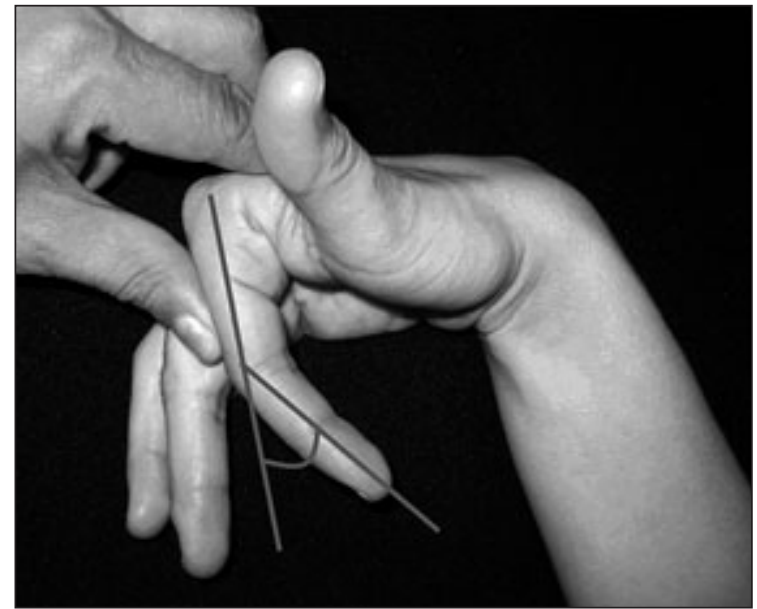

Figura 13: Test de Carducci $^{11}$.

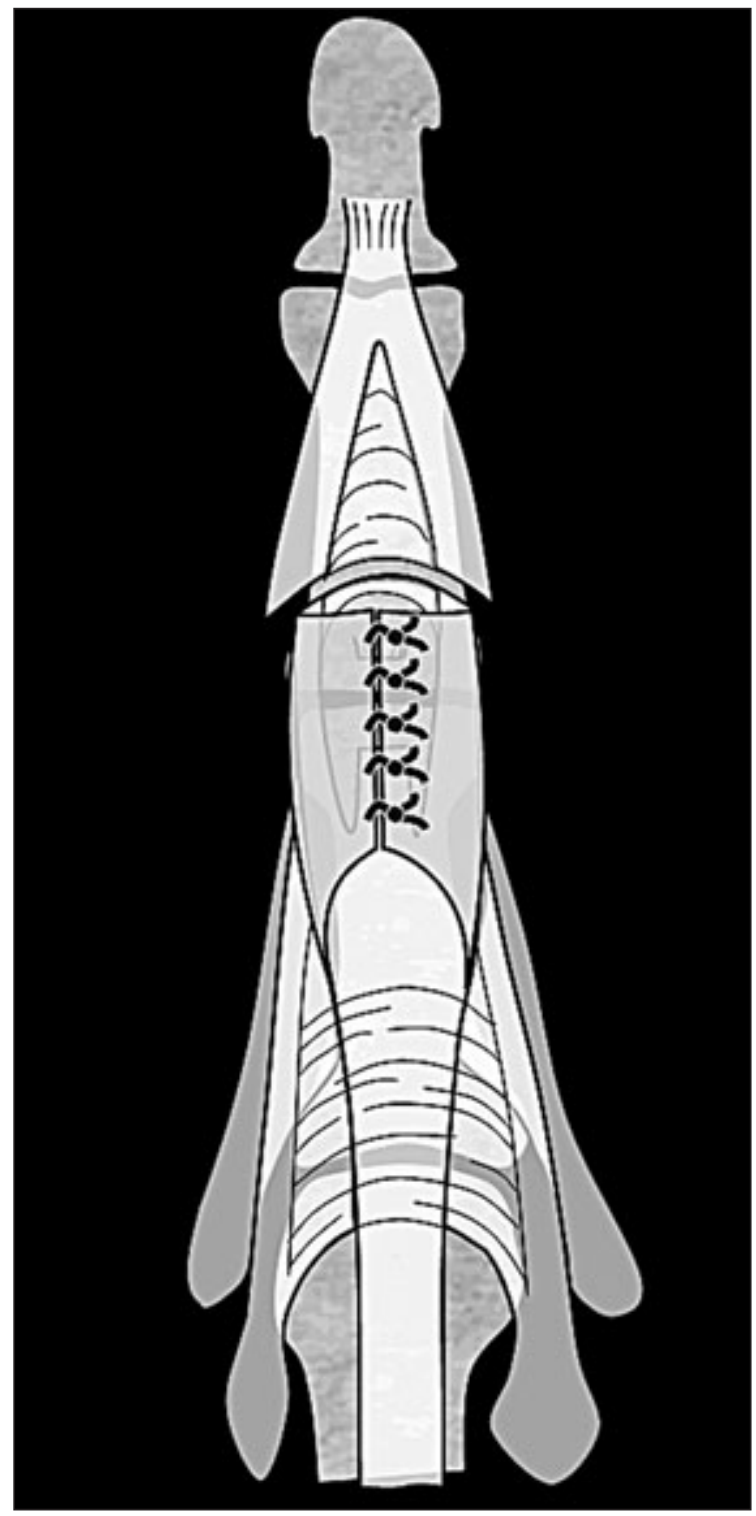

Figura 14: Técnica de Littler y Eaton ${ }^{15}$. deberemos ver qué grado de evolución y rigidez presenta. Burton y Melchior ${ }^{14}$ lo han clasificado en tres grados: En el inicial, el ojal es elástico y se corrige de forma pasiva, en el intermedio el ojal es rígido por retracción de las partes blandas y en el avanzado la rigidez es articular. Es recomendable intentar un tratamiento conservador con férula de plástico dinámica si la contractura es mayor o incluso con yesos de corrección progresivos. Estos autores insisten en tres puntos fundamentales:

- El primer punto es que, el objetivo de la cirugía es disminuir el tono extensor en la IFD y aumentarlo en la IFP.

- El segundo, que el resultado quirúrgico es mucho mejor en un dedo con las articulaciones flexibles. De hecho hay que pensar en una liberación articular previa si existe rigidez articular a la reconstrucción del ojal.

- Por último es importante valorar el estado de la articulación. La artrosis excluye la reconstrucción tendinosa, habría que pensar en este caso en la artrodesis o al artroplastia.

Dado que existen multitud de técnicas para el tratamiento de esta lesión, nosotros seguimos el esquema de la Tabla III, del cual ya se han explicado algunas técnicas. La técnica de Littler y Eaton ${ }^{15}$, consiste en realizar una tenotomía de las bandas laterales sobre la segunda falange, conservando el ligamento retinacular oblicuo. Se suturan entre sí una vez liberadas sobre el dorso de la IFP, tapando el ojal. A esta cirugía muchas veces hay que asociar otros gestos quirúrgicos para la rigidez articular como pueden ser la sección de los check-rein o recesos laterales de la cápsula volar.

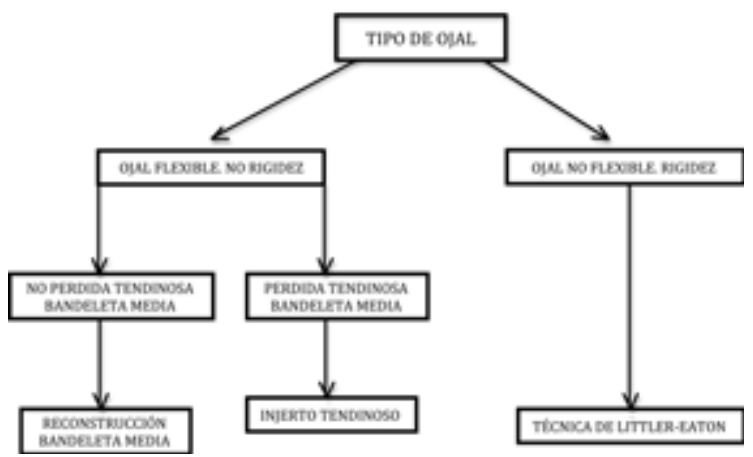

Tabla III: Esquema de tratamiento de la deformidad crónica en ojal. 
Aunque nuestra opinión personal es que, los resultados del tratamiento quirúrgico de la deformidad crónica en ojal, son bastante desalentadores.

\section{Zona IV}

En esta zona el tendón se curva alrededor de $\mathrm{F} 1$, por lo que es más frecuente que las lesiones sean parciales. Si la lesión es inferior al 50\%, el tratamiento será conservador. Si es superior al $50 \%$ recurriremos al tratamiento quirúrgico. Las lesiones agudas, cerradas y crónicas, son excepcionales. Como el tendón tiene suficiente grosor podemos realizar una sutura central tipo Kessler modificado reforzada con otra continua tipo Silfverskiöld.

El postoperatorio se puede realizar mediante inmovilización simple. Existe un protocolo diseñado por Crosby y Wehbe ${ }^{16}$ mediante férula dinámica y programa de movilización con el que parece se consiguen mejores resultados. La férula dinámica permite la flexión activa y la extensión pasiva. Se limita la flexión según lo que se aprecia intraoperatoriamente y se mantiene entre 4 y 6 semanas flexionando el dedo unas 10 veces cada hora (Figura 15).

\section{Zona V}

Debemos distinguir entre lesiones abiertas, producidas con frecuencia por mordedura, y cerradas que afectan con mayor frecuencia a las bandas sagitales.

LESIÓN AGUDA ABIERTA ZONA V: Es típico en esta zona que sea una lesión por mordedura humana sobre todo después de un puñetazo. Es una lesión muy importante por la gran probabilidad de infección, por eso el tratamiento consiste en la revisión quirúrgica, desbridamiento y lavado articular. En un segundo tiempo pasados 7-10 días se procederá al cierre.

Si no fuese una mordedura, realizaríamos el mismo tipo de sutura que en la zona IV.

Si la lesión, sea abierta o cerrada, afecta a la bandeleta sagital y el tendón extensor digitorum queda inestable sobre la MCF, realizaremos una sutura de la misma (Figura 16) con el mismo planteamiento postoperatorio que realizamos en zona IV (protocolo de Crosby y Wehbe ${ }^{16}$ ). El diagnóstico de la lesión aguda cerrada de la bandeleta sagital es difícil y si no afecta a la estabilidad del extensor, es suficiente la inmovilización de la MCF dejando la IFD libre durante 4-6 semanas ${ }^{17}$.

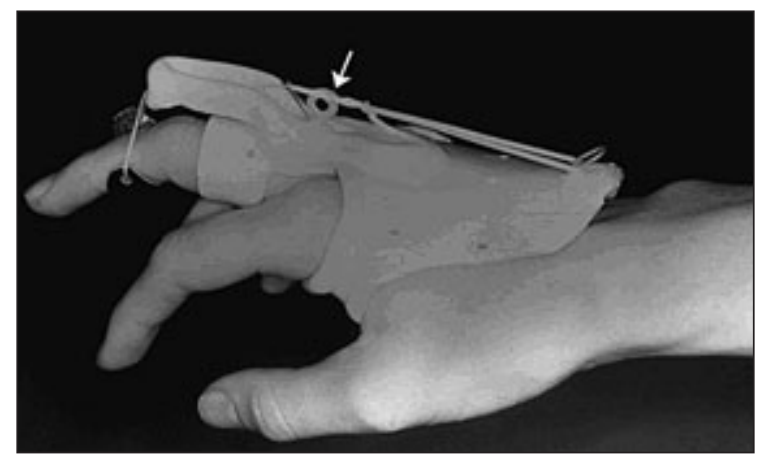

Figura 15: Férula digital dinámica.

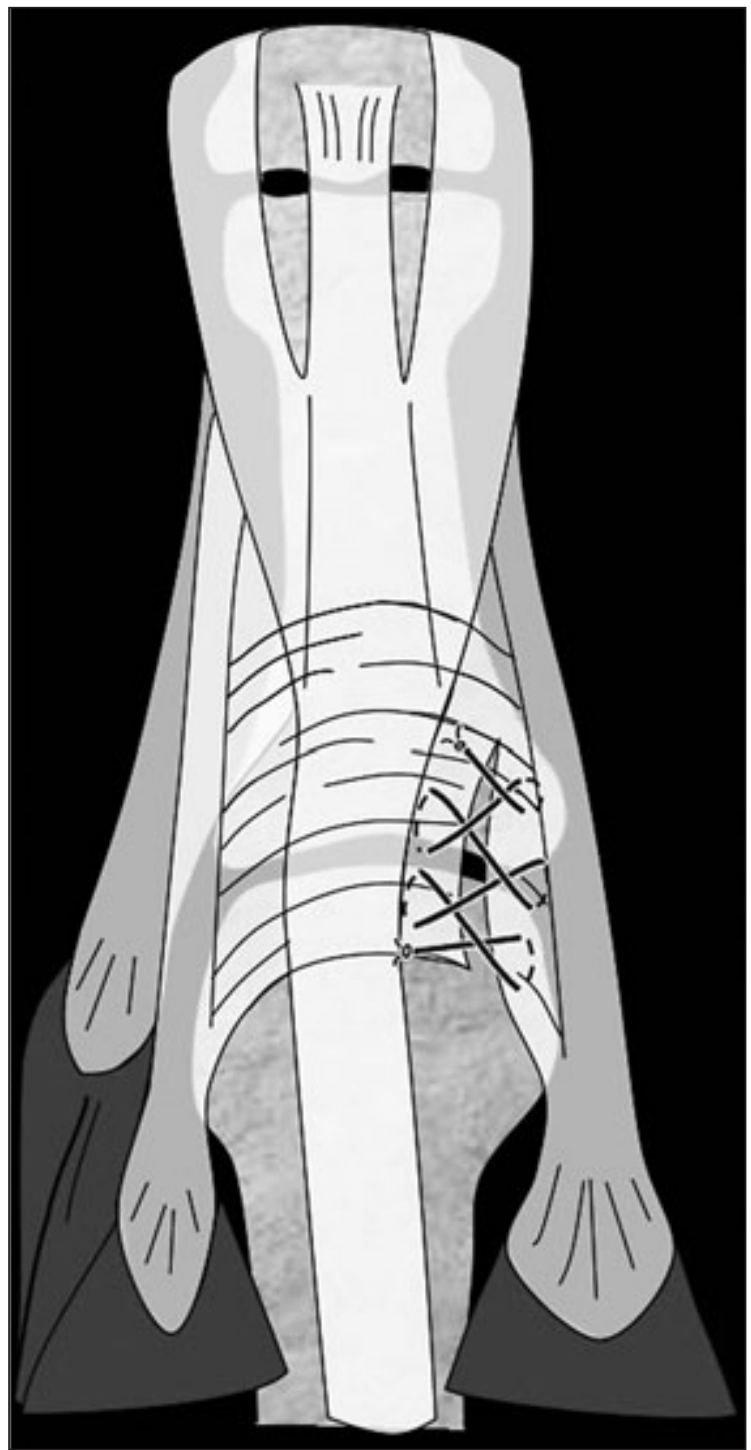

Figura 16: Sutura de la bandeleta sagital. 
LESIÓN CRÓNICA ZONA V: La rotura de la bandeleta sagital producirá una luxación del extensor que, de una manera aguda pasa con frecuencia desapercibida.

Rayan y Murray ${ }^{20}$ han clasificado las lesiones de esta zona en tres tipos:

- Tipo I: Lesión parcial de la bandeleta.

- Tipo II: Subluxación del extensor permaneciendo parcialmente unido a la cabeza metacarpiana.

- Tipo III: Luxación completa del extensor.

El tipo I corresponde más a las lesiones agudas mientras que en los tipos II y III que pro-

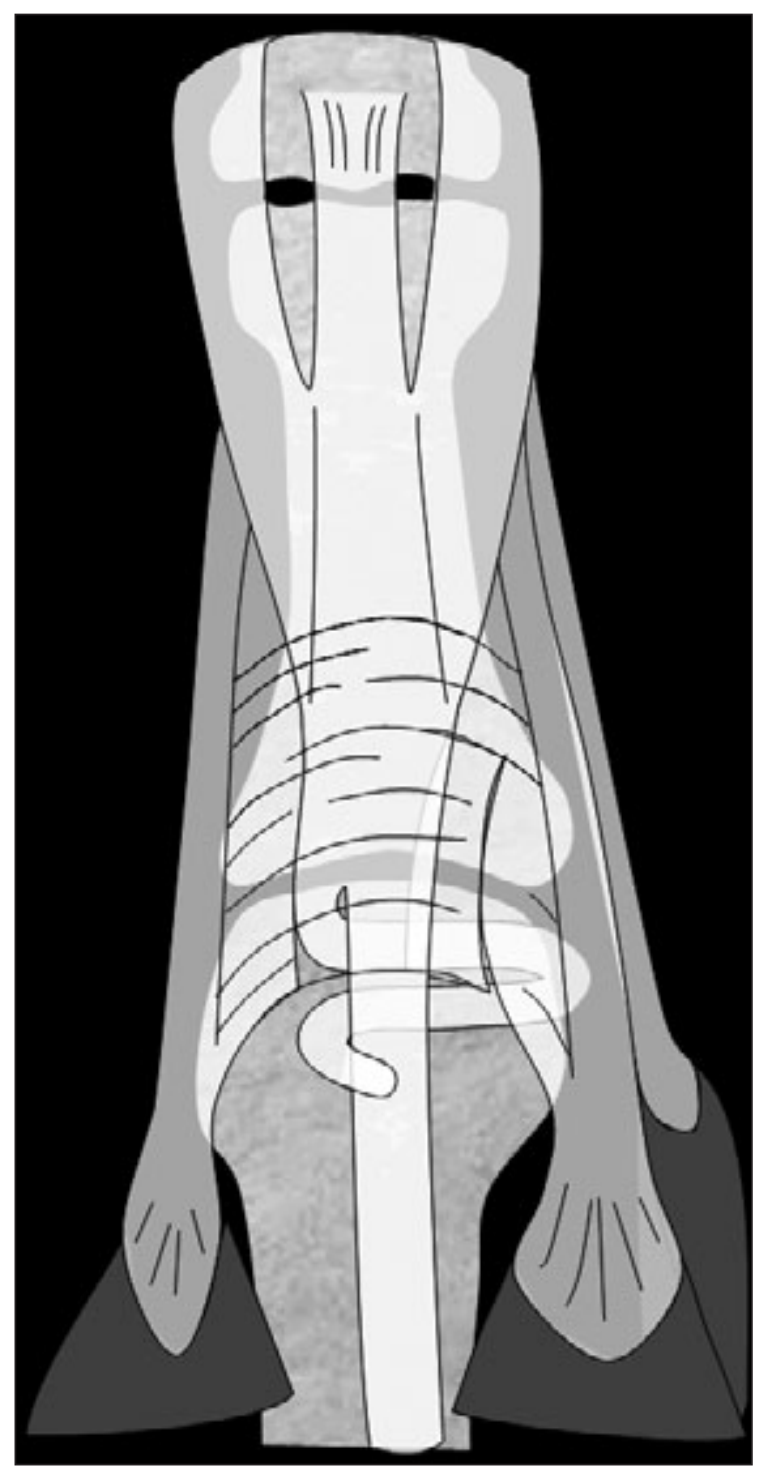

Figura 17: Plastia de Carroll ${ }^{18}$. ducen síntomas evidentes e incapacitantes deben ser tratados quirúrgicamente. Para reparar la bandeleta, existen multitud de técnicas quirúrgicas. Las más utilizadas son las plastias tendinosas de Carroll $^{18}$ y la de Mc Coy y Winsky ${ }^{19}$.

La plastia de Carroll et al. ${ }^{18}$ consiste en la extracción de un colgajo de hemitendón contralateral a la bandeleta rota, que pasamos a través del ligamento colateral contralateral y lo suturamos al tendón extensor digitorum (Figura 17).

En la plastia de Mc Coy y Winsky ${ }^{19}$ extraemos un colgajo de hemitendón del mismo lado que la lesión, y lo pasamos a través del lumbricalis para suturarlo en el extensor digitorum (Figura 18).

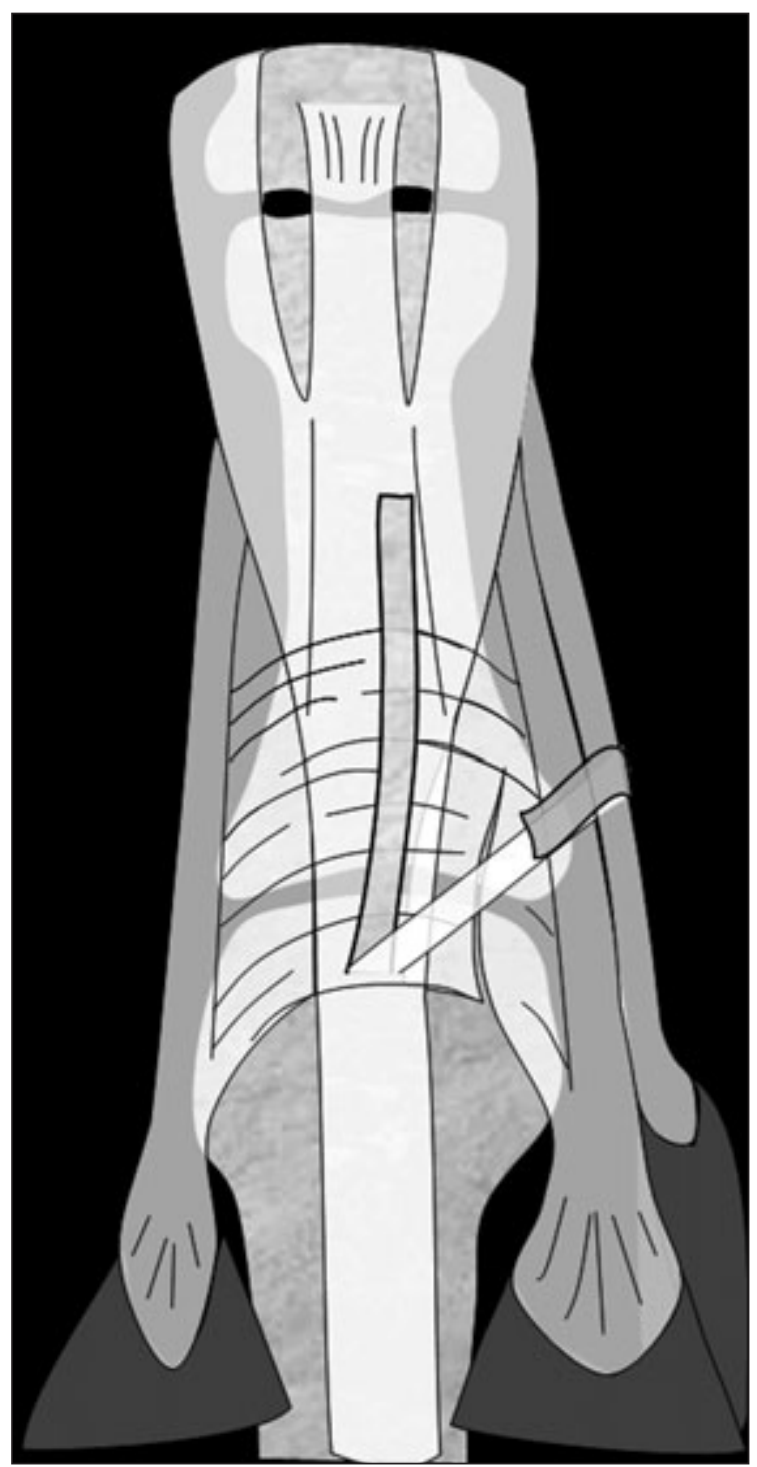

Figura 18: Plastia de Mc Coy y Winsky ${ }^{19}$. 


\section{Zona VI}

Las lesiones cerradas en esta zona suelen ser debidas a procesos reumáticos (Figura 19) o a lesiones que han pasado desapercibidas. El tratamiento en estos casos será mediante tenodesis a tendones vecinos o con injertos del flexor digitorum superficialis (Figura 20).

Para diagnosticar las lesiones agudas, es importante conocer la anatomía de la zona VI y sus distintas conexiones intertendinosas (conexus intertendineus) (Figura 21).

Si la lesión es distal a la unión el diagnóstico es sencillo, pero si es proximal la función puede ser prácticamente normal por la tracción que realiza el tendón vecino a través de la conexión intertendinosa. La sospecha se debe hacer solo por la debilidad o el déficit de hiperextensión.

En fase aguda podemos realizar una sutura tipo Kessler modificado con otra epitendinosa de refuerzo.

Si la lesión es crónica recurriremos a la tenodesis al tendón vecino o a la reparación con injertos de palmaris longus, o la utilización de flexores superficiales.

Un problema importante que plantea la zona VI es la cobertura cutánea. En caso de tener que recurrir a algún tipo de cobertura deberemos uti-

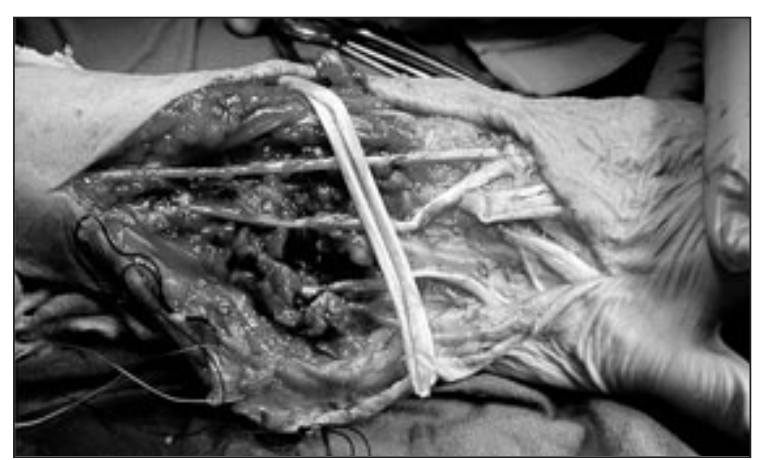

Figura 19: Rotura tendinosa múltiple en paciente con artritis reumatoide.

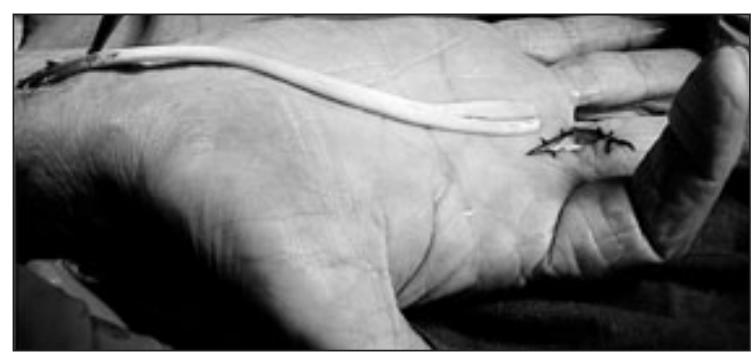

Figura 20: Injerto de flexor digitorum superficialis. lizar un colgajo, preferiblemente un interóseo posterior (Figura 22) y evitar los injertos libres de piel, dado lo superficiales que están los tendones en esta región.

\section{Zona VII}

En la zona VII son frecuentes las lesiones de varios tendones y la afectación del retináculo extensor, que a menudo deberemos resecar en parte, para poder realizar una reparación tendinosa. Es recomendable el realizar una apertura en " $Z$ " del retináculo para prevenir la deformidad en "cuerda de arco" por pérdida de continuidad del mismo, después de una sutura tendinosa (Figura 23).

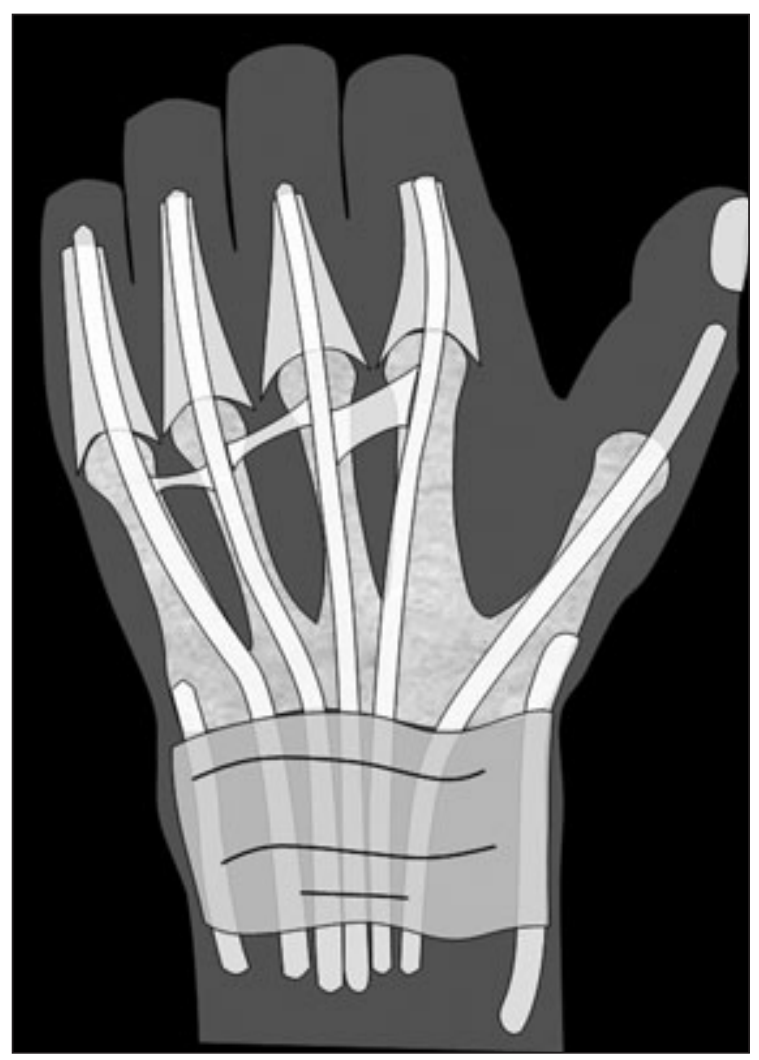

Figura 21: Conexiones intertendinosas de los extensores.

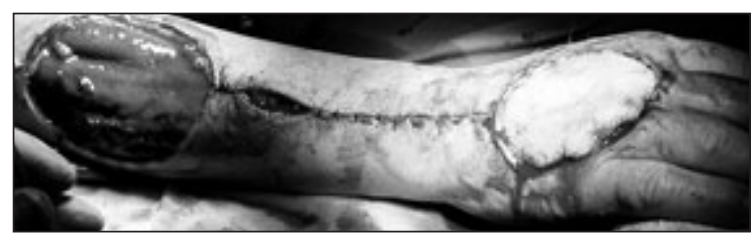

Figura 22: Colgajo interóseo posterior. 


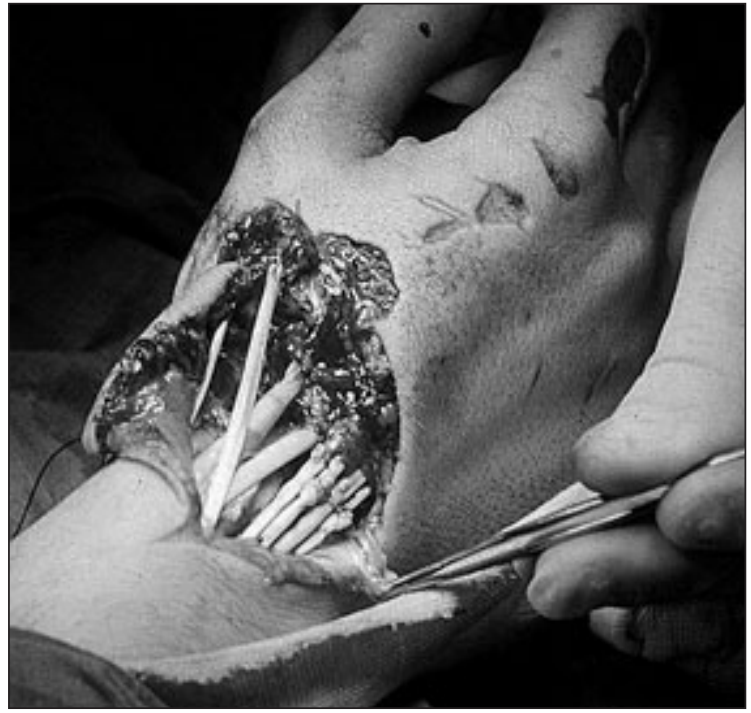

Figura 23: Lesión en zona VII.

\section{LESIONES DEL PULGAR}

Las zonas de Kleinert y Verdan ${ }^{2}$ varían en el pulgar: Las zonas impares corresponden a interfalángica (T1), metacarpofalángica (T3) y trapeciometacarpiana (T5). Y las pares a falange proximal (T2) y primer metacarpiano (T4) (Figura 24).

Zona T1: El pulgar en martillo es una lesión rara casi siempre susceptible de tratamiento ortopédico a menos que exista un fragmento óseo.

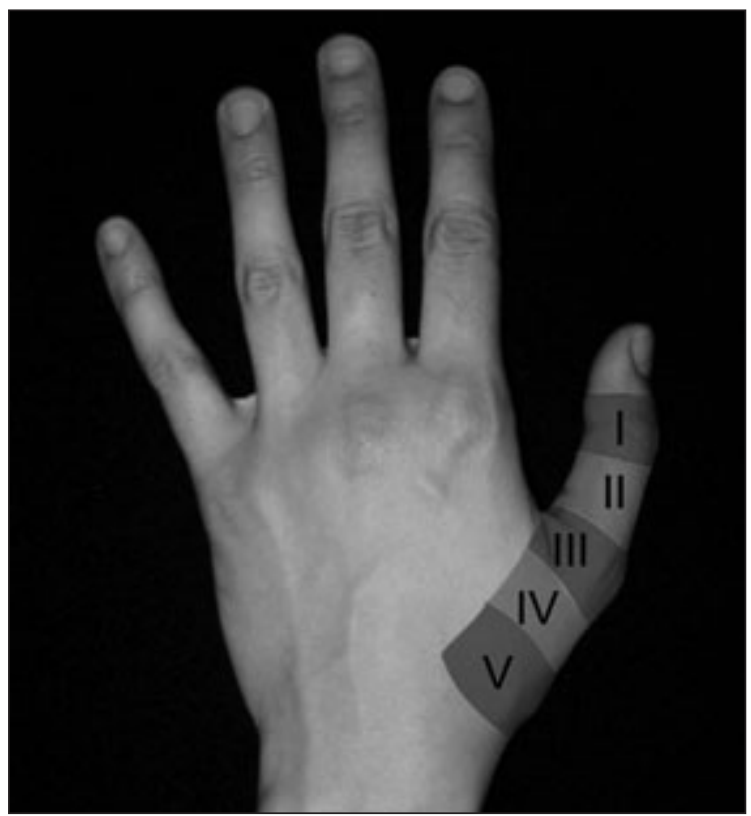

Figura 24: Zonas extensor del pulgar. En azul 1, 3 y 5 . En rojo 2 y 4.
Zona T2: Una sutura simple manteniendo la hiperextensión IF con una férula, suele ser suficiente (Figura 25).

Zona T3: Debemos reparar ambos extensores: El extensor pollicis longus y el brevis. En caso de heridas complejas o pérdidas de sustancia, realizaremos el mismo tratamiento que en zonas T4 y T5.

Zonas T4 y T5: La rotura espontánea del extensor pollicis longus en zonas T4 y T5, es la causa más frecuente de lesión del mismo. Bien

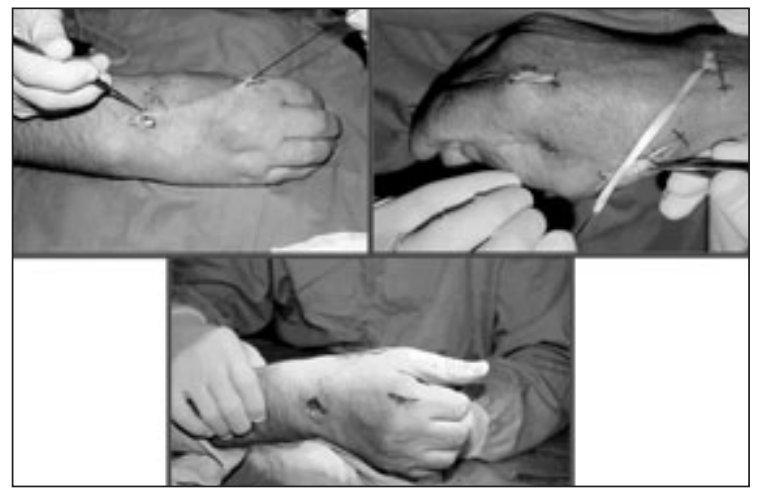

Figura 25: Transposición del extensor indicis propius al extensor pollicis longus.

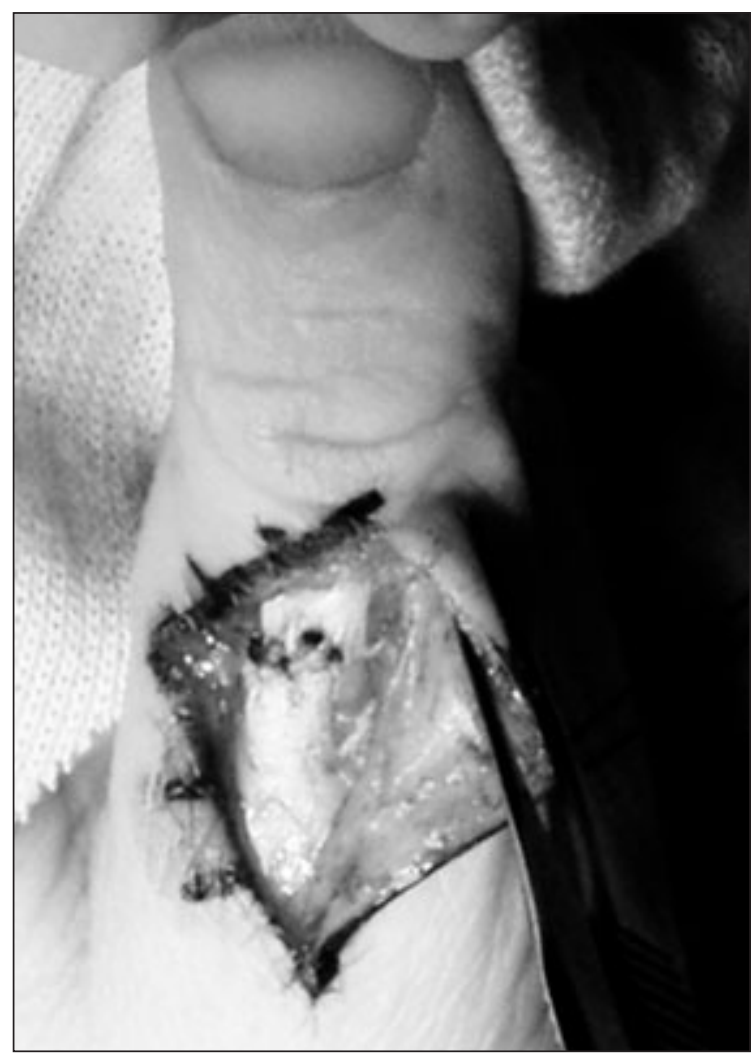

Figura 26: Sutura extensor en zona T2.

Revista Iberoamericana de Cirugía de la Mano 
debido a fracturas de la extremidad distal del radio o a otros procesos. El tratamiento que realizamos con más frecuencia es la transposición del extensor indicis propius (Figura 26), técnica sencilla y muy fiable. No tenemos experiencia en la colocación de injertos del palmaris longus ${ }^{21}$ debido a los buenos resultados conseguidos con la técnica mencionada.

\section{BIBLIOGRAFÍA}

1. Blair W, Steyers C. Extensor tendon injuries in the hand. Orthop Clin North Am, 1992; 23: 141-8.

2. Kleinert HE, Verdan C. Report of the committee on tendon injuries. J Hand Surg Am, 1983; 8: 794-8.

3. Tuttle HG, Olvey SP, Stern PJ. Tendon avulsion Injuries of the distal phalanx. Clin Orthop, 2006; 445: 157-68.

4. Ay S, Akinci M, Ercetin O. The Brooks and Graner procedure for treatment of chronic tendinous mallet finger deformity. Tech Hand Up Extrem Surg, 2004; 8: 21-4.

5. Thompson JS, Littler JW, Upton J. The spiral oblique retinacular ligament, SORL. J Hand Surg Am, 1978; 3: 482-7.

6. Doyle JR. Extensor tendons Acute Injuries. En: Green DP, Hotchkiss RN, Pederson WC (Eds). Green's Operative Hand Surgery 4th ed. New York: Churchill Livingstone, 1999: 1950-87.

7. Doyle JR. Extensor tendons Acute injuries. En: Green DP, Hotchkiss RN, Pederson WC (Eds). Green's Operative Hand Surgery, 5th ed. Philadelphia: Churchill Livingstone, 2005: 187-217.
8. Rockwell WB, Butler PN, Byrne BA. Extensor tendon: anatomy, injury, and reconstruction. Plast Reconstr Surg, 2000; 106: 1592-603.

9. Snow JW. Use of a retrograde tendon flap in repairing a severed extensor at the PIP joint area. Plast Reconstr Surg, 1973; 51: 555-8.

10. Aiche A, Barsky AJ, Weiner DL. Prevention of boutonnière deformity. Plast Reconstr Surg, 1970; 46: 164-7.

11. Carducci AT. Potential boutonnière deformity: Its recognition and treatment. Orthop Review, 1981; 10: 121-3.

12. Souter WA. The boutonnière deformity: A review of 101 patients with division of the central slip of the extensor expansion of the fingers. J Bone Joint Surg Br, 1967; 49: 710-21.

13. Evans RB. Rehabilitation techniques for applying immediate active tension to the repaired extensor system. Tech Hand Up Extrem Surg, 1999; 3: 13950.

14. Burton RI, Melchior JA. Extensor tendons-late reconstruction. En: Green PD, Hotchkiss RN, Pederson WC (Eds): Green's Operative Hand Surgery. 4th ed. New York: Churchill Livingstone, 1999; 1988-2021.
15. Litler JW, Eaton RG. Redistribution of forces in correction of boutonnière deformity. $\mathrm{J}$ Bone Joint Surg Am, 1967; 49: 126774.

16. Crosby CA, Wehbe MA. Early protected motion after extensor tendon repair. $\mathrm{J}$ Hand Surg Am, 1999; 24: 1061-70.

17. Inoue G, Tamura Y. Dislocation of the extensor tendons over the metacarpophalangeal joints. J Hand Surg Am, 1996; 21: 464-9.

18. Carroll C IV, Moore JR, Weiland AJ. Post-traumatic ulnar subluxation of the extensor tendons: A reconstructive technique. J Hand Surg Am, 1987; 12: 227-31.

19. McCoy FJ, Winsky AJ. Lumbrical loop operation for luxation of the extensor tendons of the hand. Plast Reconstr Surg, 1969; 44: 142-6.

20. Rayan GM, Murray D. Classification and treatment of closed sagittal band injuries. J Hand Surg Am, 1994; 19: 590-4.

21. Vaienti L, Merle M. Cirugía secundaria del aparato extensor de los dedos. En: Merle $M$, Dautel G, Loda G. Mano Traumática. Cirugía Secundaria. Muñeca Traumática. Barcelona: Masson SA. 1996: 93-113. 